الجمعية المصرية للقر اعة و المعرفة عضو الجمعية الدولية للمعرفة ILA

Damietta University

College of Education

Department of Curriculum \& Instruction

\begin{abstract}
A Research Paper
The Use of an Online Deep Learning Approach for Improving Self-Regulation
\end{abstract}

By

Dr. Nermeen Mohammad Kamal Shalaby

Doctor of Curriculum and Methods of Teaching English as a Foreign Language (TEFL), Damietta University, Egypt 


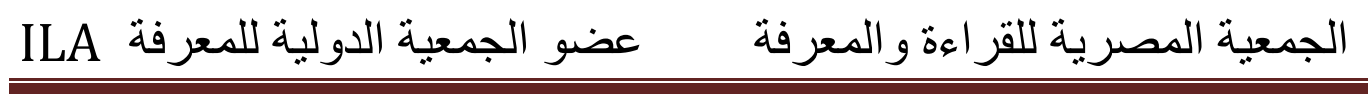




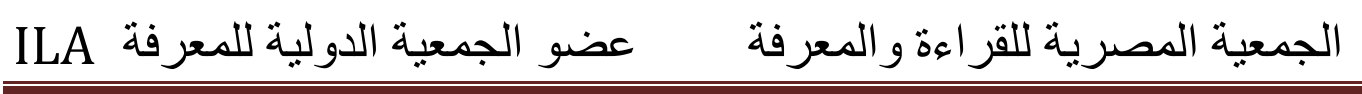

\section{The Use of an Online Deep Learning Approach for Improving Self-Regulation}

By

\section{Dr. Nermeen Mohammad Kamal Shalaby}

\begin{abstract}
The present study aimed at investigating the effectiveness of an online program based on deep learning approach for developing EFL 3rd year student teachers' self-regulation. One instrument was developed for the purpose of this study; A self-regulation questionnaire. The participants of the study consisted of sixty students selected at random from EFL 3rd year student teachers at Faculty of Education, Damietta University in the academic year 2019/2020. The study adopted the quasi-experimental research design. Therefore, the participants were randomly assigned into two groups: an experimental group $(n=30)$ and a control one $(n=30)$. The experimental group received training through the program based on an online deep learning approach designed by the researcher. On the other hand, the control group received instruction through the regular method. Participants were pre- and post-tested on the instrument: self-regulation questionnaire (SRQ). Results revealed that the experimental group outperformed the control group in the post administration of the self-regulation questionnaire. The study concluded that the online program based on deep learning approach enhanced EFL 3rd year student teachers' self-regulation. A number of conclusions, recommendations and suggestions for further studies were presented.
\end{abstract}

Keywords: Deep Learning Approach, Online Learning, and SelfRegulation

1. Background and Problem

1.1. Introduction 
For achieving success, learners of English need to have an ability that helps them to monitor, and self-control their behaviors. One basic factor, which plays an important role in self-development and language learning, is self-regulation. Ozhiganova (2018) emphasizes that self-regulation is generally defined as a "capacity" that refers to an individual's ability to extend control over their behavior, thoughts, feelings, desires, impulses and emotions in accordance with the rules of human interaction, helps to release the possibility of energy for selfless service to the society, and contribute to the productivity and quality of life. She adds that selfregulation is associated with reflection, self-awareness, emotional and optional processes, goal setting with the achievement of significant goals, the higher capacity to open the way to spiritual growth and inner experience, leading to self-development and the realization of the meanings and purposes of life.

Ley and Young (2001) mention that self-regulation components are setting goals, preparing a place to study, organizing materials, monitoring learning, evaluating progress and effectiveness, and reviewing tests, which manage and direct personal behavior to achieve complex academic tasks independently. Furthermore, Horner and Shwery (2002) contend that engaged self-regulated readers set goals that are short-term, specific, and attainable; select effective reading strategies effectively; monitor their comprehension during reading of the text; and self-evaluate progress toward their goals. Moreover, they report that teachers develop students' selfregulated reading skills through the methods of modeling, coaching, scaffolding, articulation, reflection, and exploration. In addition, students' personal beliefs about their self-efficacy, task value, and motivational orientation will influence their level of self-regulation. Thus, self-regulation processes, personal beliefs, and motivation are all interrelated and reciprocal. 
The development of self-organization requires a type of learning with special characteristics that depends on investing the learner's abilities such as analyzing, synthesizing, understanding of relationships and positive interaction between the reader and the reading text. This is provided by a type of learning that has recently been referred to as "deep learning". According to Biggs (1987) and Biggs, Kember and Leung (2001), deep learning consists of deep motive and deep strategy. Deep motive means an interest in learning or enhancing one's ability to learn. Deep learning means to seek for meaning to understand by reading widely and to relate the new knowledge to the previous knowledge or experience. Also, Leamnson (2004) indicates that deep learning is the kind that demands both understanding and remembering of relationships, causes, effects and implications for new or different situations simply cannot be made easy. Such learning depends on restructuring the students' brains; a process which demands great effort.

At the current age, reading is no longer limited to paper texts but it includes online interactions. It allows many students and teachers to interact with various scientific materials and discover new contents, concepts and ideas. Rossen and Hartley (2001) consider online learning as a type of e-learning which has some advantages. It allows learners to control their learning by discovery and self-navigation, and to access for a synchronous training from any place in the world with very little technology. It also saves the costs of travel; and provides flexibility in scheduling and speed in delivery.

\subsection{Statement of the Problem}

Based on the literature review, the pilot study, the researcher's experience and the digital transformation of learning and development. It is evident that EFL $3^{\text {rd }}$ year student teachers at Damietta Faculty of Education need improvement in self-regulation processes. Therefore, the present study was to investigate how far 
using an online program based on deep learning approach could develop self-regulation of the target sample.

\subsection{Research Questions}

1. What are the self-regulation processes necessary for EFL $3^{\text {rd }}$ year student teachers?

2. What are the components of an online deep learning based program to develop EFL 3rd year student teachers' and selfregulation?

3. What is the impact of an online deep learning based program on developing EFL $3^{\text {rd }}$ year student teachers' self-regulation?

\subsection{Hypotheses}

1. There is a statistically significant difference, at the significance level of $p \leq 0.05$, in the self-regulation post-questionnaire, between the mean score of the experimental group and those of the control group in favor of the experimental group.

2. There is a statistically significant difference, at the 0.05 level between the self-regulation performance of the experimental group on the pre-and post-administration of the self-regulation questionnaire in favor of the post-administration.

\subsection{Purpose}

1. Identifying self-regulation processes necessary for EFL $3^{\text {rd }}$ year student teachers.

2. Determining the most important deep learning strategies that emerged from the deep learning approach.

3. Designing and implementing an online program based on deep learning approach for developing EFL $3^{\text {rd }}$ year student teachers' selfregulation. 
4. Investigating the effectiveness of an online program based on deep learning approach for developing EFL $3^{\text {rd }}$ year student teachers' self-regulation.

\subsection{Significance}

1. Raising EFL $3^{\text {rd }}$ student teachers' awareness of the importance of using online learning and deep learning approach in learning the English language.

2. Developing EFL student teachers' performance in the selfregulation processes.

3. Providing guidelines for designing programs that aim at improving EFL student teachers' self-regulation in the four academic years.

4. Providing EFL educators with an online deep learning based program for promoting students' self-regulation processes.

\subsection{Delimitations}

1. A sample of students from EFL $3^{\text {rd }}$ year student teachers at Damietta Faculty of Education, in the academic year 2019/2020, who were assigned at random into two groups: an experimental group and a control one.

2. Self-regulation processes appropriate for EFL $3^{\text {rd }}$ year student teachers (planning and activation, performance, monitoring, and selfreflection and reaction).

3. Selected Deep learning strategies that emerged from the deep learning approach (jigsaw strategy, AICDR strategy, graphic organizer strategy, and talk show strategy).

\subsection{Design}

The present study follows the quasi-experimental design to investigate the effectiveness of an online deep learning based program to develop EFL $3^{\text {rd }}$ year student teachers' self-regulation. Two groups from EFL $3{ }^{\text {rd }}$ year student teachers at Damietta Faculty of Education, are selected at random to represent the experimental 
and control groups. The experimental group will receive instruction through an online deep learning based program to develop selfregulation. On the other hand, the control group will receive instruction through the regular method. Moreover, the experimental and control groups will be subjected to a pre-post self-regulation questionnaire, prepared by the researcher.

\subsection{Instruments and Materials of the study}

1. A self-regulation processes questionnaire.

\subsection{Definition of Terms}

\subsubsection{Deep Learning Approach:}

Kollerup (2015, p.3) defines a deep learning approach as an approach where learners actively engage in the learning process that includes critical analysis, understanding and application of knowledge. In addition, Hermida $(2016, \mathrm{p} 1)$ defines a deep learning approach as an approach where the reader uses higher-order cognitive skills such as the ability to analyze, synthesize, solve problems, and thinks meta-cognitively in order to realize meanings with the author and to construct new meaning from the text. The deep reader focuses on the author's message, on the ideas he/she tries to convey, the line of argument, and the structure of the argument. The reader makes connections to already known concepts and principles and uses this understanding for problem solving in new contexts.

The present study refers to deep learning approach as a type of learning that encourages higher-order cognitive levels of mental processes during reading different texts. This exceeds the level of literal understanding of these texts to connect new knowledge with prior experience; convey evidence to conclusions; understand and apply the concepts; and critique arguments.

\subsubsection{On-line learning}

University of Massachusettes (2002) defines online learning as faculty-delivered instruction via the Internet. Online instruction includes real-time (synchronous) and anytime, anywhere 
(asynchronous) interactions. Furthermore, Bakia, Shear, Toyama and Lasseter (2012) defines online learning as instructional environments supported by the Internet. It comprises a wide variety of programs that use the Internet within and beyond school walls to provide access to instructional materials as well as facilitate interaction among teachers and students. It can be fully online or blended with face-to-face interactions.

The present research refers to on-line learning as instructional environments which allow varied interactions with the assistance of the internet in real or delayed time to achieve educational goals.

\subsubsection{Self-regulation}

Zimmerman (2000) defines self-regulation as self-generated thoughts, feelings, and actions that are planned and cyclically adapted to the achievement of personal goals.

Also, Allen (2011, p.7) defines self-regulation as recurring process in which learners can monitor and affect their learning outcomes and goals. This process requires learners to adjust and adapt their strategies and skills when having a difficulty in learning new information.

The present research refers to self-regulation as the learners' ability to generate emotions, feelings, thoughts and actions, and monitor and evaluate their own behavior in accordance with the personal goals and learning outcomes.

\section{Review of Literature}

\subsection{Self-Regulation and Technology}

Numerous studies asserted the relationship between technology and self-regulation. In a study conducted by Naseri and Motallebzadeh (2016), they found that employing technological 
devices in learning a language can enrich learners' self-regulation ability. In another study conducted by Barak, Farraj and Dori's study (2016), they found that online courses provide flexibility in time, place and pace; give a plenty of freedom, autonomy, and control that make learners self-regulate their learning and deepen their understanding. Therefore, self-regulation in distance learning environment influences both instructors and students and leads to positive learning outcomes. As well as, Barboza, Torres, Nunez and Martinez's study (2017) revealed the importance of digital tools especially personal learning environments for developing selfregulation in all three phases and fostering social relationships that influence its individual processes.

Moreover, Bartolome and Steffens (2011) shed light on some different technologies that support self-regulation learning as following:

a) ePortfolios save students' activities, products and teacher feedback ; and evaluate their learning outcomes.

b) Blogs give flexibility to students, and help them to look for resources to support their learning.

c) Wikis provide students relevant information, enable them modify content collaboratively with others online from the web browser, and record group's interaction and its progress over time.

d) Virtual environments contain many tools and resources for fostering self-regulated learning.

e) Personal learning environments (PLE) contain collections of tools and services, and achieve individualization of training and learning. Each learner builds his own working space according to available resources from educational institutions, and web services. 


\section{الجمعية المصرية للقر اعة والمعرفة عضو الجمعية الدولية للمعرفة}

f) Web 2.0 is admitted across the curriculum in many different domains and based on multi-media.

Furthermore, Kitsantas (2013) presented a training model that was used for developing students' self-regulatory competence with learning technologies as shown in figure1. In the first phase, observation, students carry on the task step by step to develop their basic understanding of the skills, build up basic strategies and plans for learning. In the second phase, emulation, students are learned to emulate the task by the model and are provided with support, encouragement, and feedback from peers and instructors. In the third phase, self-control, students begin to practice the skills independently and monitor their progress towards mastery. Finally, in the fourth phase, self-regulation, students shift from processoriented goals to outcome-oriented goals.

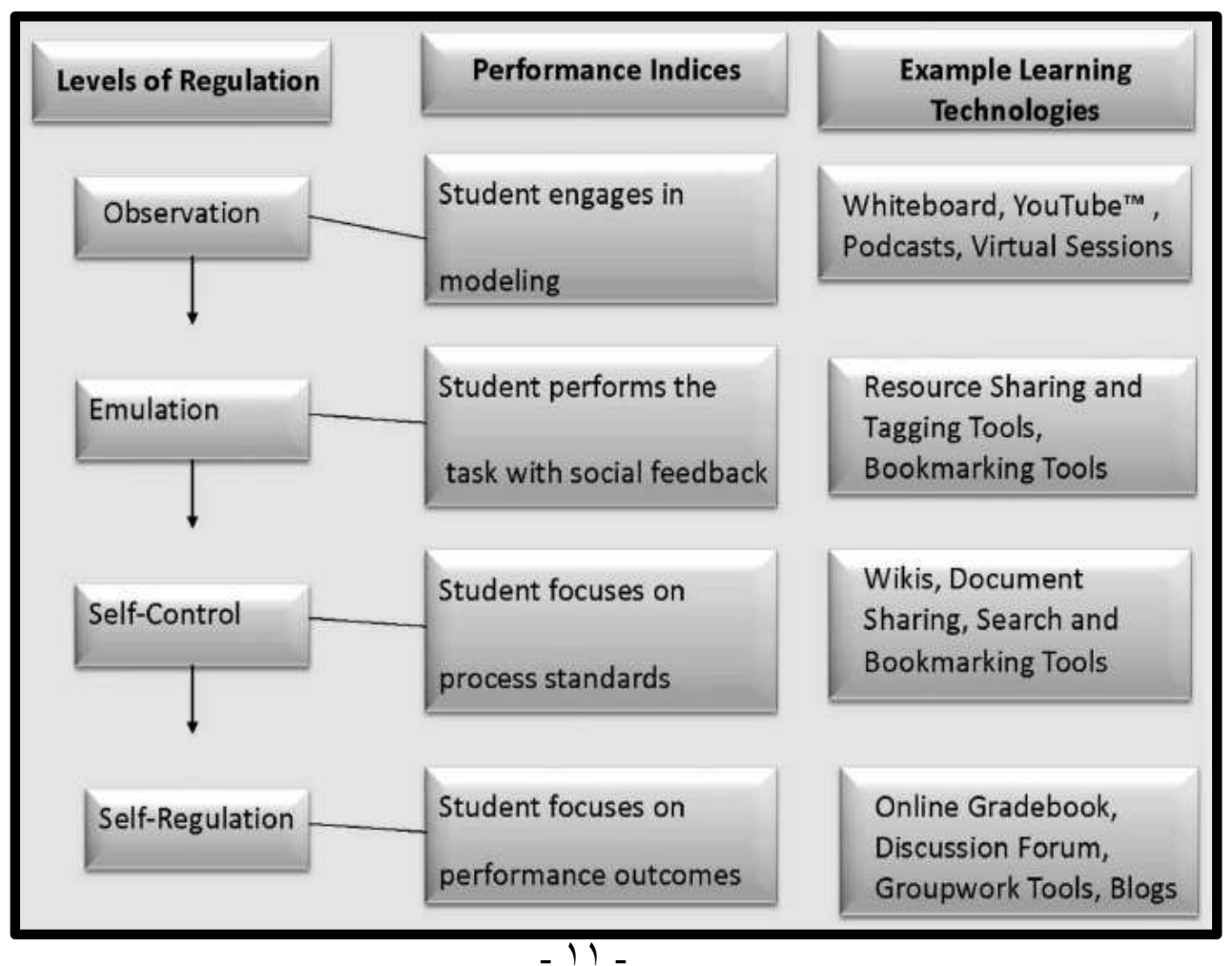




\section{الجمعية المصرية للقر اعة والمعرفة عضو الجمعية الدولية للمعرفة}

Figure1. Development of Self-Regulation with Learning Technologies.

Source: Kitsantas (2013, p. 246)

In brief, self-regulation and technology associate with each other. Learners need to utilize different technological applications to self-control, manage, monitor and self-regulate their behaviors. Thus, virtual learning environments let learners deepen their knowledge and acquire self-confidence.

\subsection{Promoting Self-Regulation in the Classrooms and in Online Courses}

Most instructors seek to rehearse their learners to self-regulate in achieving the academic tasks. Paris and Paris (2001) explain some basics of self-regulated learning to promote in classrooms: a) Selfregulation leads to deeper understanding of learning; b) It can be taught in many ways; c) It is acquired from authentic or repeated experiences in school, explicit instruction, engagement in practices that require self-regulation; d) It is elicited through projects, portfolios and performance assessments that enhance creative expression. e) Self-management of thinking leads to use flexible approaches that are adaptive, persistent, self-controlled, strategic, and goal-oriented.

Sahabudin and Ali (2012) maintain that self-regulated learning is not only applied in traditional learning, but also applied in learning based on internet technology. As well as, Kitsantas (2013) reports that learning technologies promote college students' self-regulation in online learning environments in higher education and enhance motivation for improving academic performance, positive attitude 
towards learning. Therefore, they support students' self-regulatory processes within the three cyclical phases of self-regulation model, forethought, performance, and self-reflection. For example, in the forethought phase, instructors can use administrative tools including course calendar, course planning and scheduling tools. In the performance phase, instructors can encourage students to use Web publishing tools, social book marking tools and Wikis. In the selfreflection phase, instructors can use blogs to enhance student understanding of content by taking their reflections on readings enabling them self-monitoring and self-evaluation.

To sum up, self-regulated learning leads learners both in traditional classrooms or virtual learning environments to acquire meaningful experiences through using flexible techniques that enable them to be goal-oriented, self-controlled, self-motivated, and self-evaluated.

\subsection{Best Practices in Online Learning Environments}

Reviewing previous studies findings showed that online learning not only has more successful learning practices than traditional learning but also provides distinguished instructional opportunities. For instance, Means, Toyama, Murphy, and Baki's study (2013) investigated the effectiveness of online learning in general, and both purely online and blended versions of online learning in particular as compared with traditional face-to-face learning, for a variety of learners and with a range of different contexts and practices. This meta-analysis study revealed that online learning produced better student learning outcomes than face-to-face instruction. Moreover, learning practices (such as the duration of the intervention, provision of synchronous computer-mediated communication, and the incorporation of learner feedback) exposed how online learning was implemented (e.g., whether online students had the opportunity to interact with an instructor). Meanwhile, 
Chang's study (2002) examined the effectiveness of asynchronous online learning in the promotion of critical thinking indicators (authenticity, community, reflection, and multiple perspectives) and students' perceptions of opportunities for critical thinking on three online courses at a distance education program at a major university in New York City. This study revealed that asynchronous online learning could support critical thinking with the support of constructive instructional design, cooperative/collaborative learning, critically reflective learning strategies, and the opportunity to engage multiple perspectives.

In addition, Lindblom-Ylanne and Pihlajamaki's study (2003) investigated whether a computer supported learning environment enhances essay writing by providing an opportunity to share drafts with mate students and receive feedback from a draft version. Twenty-five law students participated in this qualitative study. Data for this study were collected by both the students' and the teachers' interviews. The results showed that the students could deepen their understanding, express their own ideas, improve critical thinking skills, and develop self-regulation. Furthermore, Xiaoming and Zhuo's study (2017) examined a proposed comprehensive method to implement online virtual experiments that incorporates learning assessment and course design based on the unique nature of virtual experiment. The results showed that students could control the pace, frequency, time of the experiment and evaluate their learning achievements effectively, develop their autonomous learning ability, and combine theory with practice for improving their learning efficiency greatly. Moreover, Hanover Research Council (2009) mention best practices in online strategies can be organized into three major components of the instructional process as following:

1. Best practices in planning and development:

The planning process involves the best technological option suited for the online course to create a learning community among students and the instructors. Moreover, teaching methods include training in 
technology for distance learning, interactive teaching that fosters critical dialogue, mentoring, and cooperative peer learning.

2. Best practices in teaching-in-action:

Distance education provides many opportunities to foster an interactive classroom through two techniques: (1) online discussion forms that promote constructivist thinking, critical thinking, and higher-order thinking, and (2) student collaboration that relies on the use of educational technologies to simulate face to face meetings when students work together on assignments.

3. Best practices in student assessment and data evaluation :

- Assessment through an evaluation process that uses several methods and applies specific standards for student learning.

- The regular review of intended learning outcomes to ensure clarity, utility, and appropriateness.

- Timely evaluations at regular intervals to increase course flexibility for students.

- The assurance that monitoring/proctoring policies are in place during assessments of student learning.

- Assessment strategies are integral to the learning experience, enabling learners to assess their progress, identify areas for review, and re-establish immediate learning or lessons goals.

- Strategies are varied (self-tests, quizzes, journals, writing assignments, projects, exams, etc.) and aligned to instructional goals. - Assessment criteria are clearly articulated.

To sum up, best practices that occur in online learning enable learners to be responsible for their learning and proactive to engage actively in different courses and programs by using its diverse tools. As well as, online instructors seek to foster these practices by attracting learners' attention to the best usable strategies and techniques.

\subsection{Deep Learning Strategies}

\subsubsection{Jigsaw Strategy}

Jigsaw is a cooperative learning strategy that facilities the communication process among learners. Hedeen (2003) considers 
jigsaw as a process that happens in four essential steps : 1) First, students gather in 'jigsaw groups' of three to six and the material is divided to be covered within each group, 2) Next, each member of the group studies the specified section in jigsaw group, 3) Then, students form 'expert groups' by gathering with members of other jigsaw groups who are provided the same section of the material to discuss and plan how they will teach to other members of their jigsaw groups, 4) At last, students return to their jigsaw groups to teach their learned materials to their group and to learn the materials taught by other members.

Perkins and Saris (2001) introduce some benefits of jigsaw technique. It helps students expand the variety of learning experiences ; acquire positive attitudes towards the subject of the study; improve their achievement; get and give help; increase contact, cooperation and support; become collaborative learners; save time more efficiently; teach others; and make active responses.

Several researches stressed the affective influences of Jigsaw on EFL students' language learning. For example, Keshta's study (2016) investigated using jigsaw strategy on improving reading comprehension and communication skills among eleventh graders in Rafah and revealed that there were significant differences in learning English reading comprehension and communication skills between both groups: the experimental and the control ones, in favor of the experimental group due to using the jigsaw strategy.

Thus, all the previous investigations confirm that Jigsaw technique develops students' language skills, their competency in English; encourages cooperation and engagement; improves their attitudes and motivations towards English learning; and increases self-confidence.

\subsubsection{AICDR strategy}

Ask Investigate Create Discuss Reflect strategy is one of the interactive processes of inquiry based learning. It is based on engaged learning and the building of knowledge. It is profitable for 
students' thinking and learning (Friedman, Crews, Caicedo, Besley, Weinberg \& Freeman, 2019). Edutech Wiki (2019) introduces AICDR strategy as an inquiry cycle which has five steps: Ask, Investigate, Create, Discuss and Reflect; engages students to ask and answer questions on the basis of collected information; and leads to the creation of new ideas and concepts.

According to Li, Moorman and Dyjur (2010), the inquiry process starts with meaningful questions inspired by students about real world experience. Then, they investigate by gathering information and interviewing to answer the questions. After that, they act the creative task by integrating ideas and important thoughts to create new knowledge. Next, they discuss their ideas with others and build information through shared knowledge. Finally, they step back, reflecting on the questions and the research path, and make new decisions. Casey and Bruce (2011) show that the stages of inquiry cycle are mutually reinforcing and interrelated; and are used to inform and guide educational experiences for learners. In addition to that, they add that digital media practices can enrich the inquiry cycle by offering new entry points such as taking pictures, and facilitating different modes of experience and engagement such as visual, aural enrichment, narrative, music, text and symbols.

In this respect, Bruce and Bishop's study (2003) showed the effectiveness of using web to support inquiry-based literacy development. Therefore, the students used an inquiry page as a website for collaborative curriculum development through the creation of inquiry units. These units become starting points for inquiry through which students are encouraged to ask questions, investigate, create, discuss, and reflect. This inquiry page was also used for supporting the integration of knowledge across a community of inquiry, providing a means for all students to collaborate and learn from one another, and developing an active digital library. 
To sum up, AICDR strategy is an inquiry process which consists of five stage: Ask, Investigate, Create, Discuss, Reflect. These stages are mutually reinforcing and interrelated. This strategy helps students to enrich intellectual engagement and deep understanding; develop their self-belief on their selves; and build up their interest, motivation and creativity. Moreover, Both teachers and students can use digital media practices to enhance it in teaching and learning.

\subsubsection{Graphic Organizer Strategy}

Graphic organizer is a teaching and learning strategy that is used to organize information and ideas. Kaufman and Wandberg (2010) illustrate that graphic organizers are visual representations of information, facts, concepts and skills that are linked, or not linked, together. They are sometimes called mind maps, webs, or visual organizers. Their styles are readily available to support common patterns of information. As well, they are adaptable to virtually all content areas, grade levels and student ability levels, and especially helpful with special education students and English language learners. In addition, graphic organizers can be effectively used during many phases of instruction: at the beginning of the lesson as a way to activate prior knowledge, during the lesson to achieve both content objectives and language objectives, and at the end of the lesson for student assessment and evaluation purposes.

Ellis (1999) indicates that graphic organizers are communication devices that show the relationships between concepts. They shape content easier to understand and learn, reduce information-processing demands, and make students more strategic. $\mathrm{He}$ adds that there are four stages for enabling students to construct them. The first stage is "teacher does it" to provide students a copy, and use it when teaching the content. The second stage is "class does it" to explore the new content by depicting important ideas. The third stage is "groups do it" via cooperative learning and the teacher acts as a guide-on-the-side. At last, the fourth stage is "individuals do it" by constructing a graphic organizer independently. 
Various studies emphasized using graphic organizers for developing students' language skills. For instance, Tobar and Moya's study (2017) analyzed different studies on the research findings and issues about using graphic organizers as a reading strategy. It revealed that teachers should implement this reading strategy in their classrooms and train students in using it to be better readers, develop their reading comprehension, promote their autonomous learning, and achieve higher levels of performance. In addition to that, Torres's study (2015) investigated the effectiveness of using graphic organizers for improving EFL Students in a reading comprehension course. The results showed that students' reading skill developed very well. Graphic organizers should be used as a while-reading strategy.

In conclusion, graphic organizers are communication tools that indicate the relationships between the different parts in the text, develop students' critical thinking, relate students' prior knowledge to new knowledge to create meaningful learning, encourage students' understanding and perception as well as develop their reading comprehension skill. Hence, it is still fundamental to adopt for all ages by different kinds to support various organizational patterns of information.

\subsubsection{Talk Show Strategy}

Talk Show is a new English Language Teaching (ELT) strategy that deepens students' understanding and makes learning more enjoyable. Nimehchisalem (2013) interprets that talk show strategy is a learner-centered strategy enables the teacher and students participate in an imaginary television program similar to that of a television talk show. The teacher may become the "host"; one or more students may become "guests" who are popular experts in a specific area. The other students can choose to be "audiences/viewers" as members of the studio audience or home viewers who are allowed to call in or write to the host in order to ask questions, criticize, or share ideas. 
Ilie (2006) mentions that talk shows bring together, through the intervention of a host, a guest panel (experts and participants), a studio audience and sometimes an audience of 'callers'. As well, they have some major criteria to take into consideration: (1) discussion topics; (2) categories of participants; (3) broadcasting time; (4) organizational and interactional frameworks; and (5) ethical considerations.

Many studies stressed using talk shows for improving students' learning. For example, Syahadati's study (2015) investigated the use of talk show video as a reflective practice to improve students' vocabulary in English speaking skill. The results revealed that talk show video in teaching and learning English could improve the students' vocabulary in speaking skill in which students paid attention toward the lesson and encouraged to use English in teaching learning speaking by allowing them to record the talk show and watch what they have done. Thus, talk show video could stimulate and motivate students' interesting in improving their vocabulary in speaking class.

Besides, Liao's study (2011) investigated the use of TV talk show in developing students' oral communication ability. The results revealed that TV talk show strategy could develop students' oral communication skills by coherent communication situations in the actual exchange of information; and stimulate their enthusiasm greatly in the training to have entertainment and fun, inspire new ideas, and cultivate their personality.

In brief, talk show strategy is an interactive structured process that requires preparing and planning the show, simulating the show as TV program, and reviewing the show to assess and evaluate the performance. As well, talk show strategy makes learning meaningful, enjoyable and dynamic, develops learners' skills and self-abilities, relates learning with technology, and improves learning outcomes.

Different categories of deep learning strategies have been discussed. Teachers should select the most important ones to help 
them in teaching in the traditional classrooms or in the virtual learning environments, promote students' understanding and abilities, develop their critical thinking and lifelong learning skills, foster their self-confidence and self-regulate themselves towards learning.

\section{Methods and Analysis}

\subsection{Validity of the Self-Regulation Questionnaire}

\subsubsection{Face Validity}

To measure questionnaire content validity, the present researcher made use of face validity where the jurors decided on: a) statement of the questionnaire items; b) suitability of questionnaire items for assessing self-regulation processes; d) suitability of questionnaire items for the EFL $3^{\text {rd }}$ year student teachers' level; d) any other comments or suggestions.

\subsubsection{Construct Validity}

To calculate the construct validity of the SRQ, the researcher used Pearson Statistical Formula as follows:

a. Using Pearson Correlation, the researcher estimated the correlation coefficient of the grade of each item with the total score of the self-regulation process. The results are shown in table1.

\section{Table1.}

Construct Validity of the $S R Q$

\begin{tabular}{ccc}
\hline Processes & Items & $\begin{array}{c}\text { Correlation } \\
\text { coefficient (r) }\end{array}$ \\
\hline \multirow{2}{*}{ Planning and Activation } & Item1 & $0.89 * *$ \\
& Item2 & $0.73 * *$ \\
& Item3 & $0.57 * *$
\end{tabular}




\begin{tabular}{ccc} 
Item4 & $0.84 * *$ \\
Item5 & $0.84 * *$ \\
Item6 & $0.80 * *$ \\
Item7 & $0.57 * *$ \\
\hline \multirow{3}{*}{ Performance } & Item8 & $0.81 * *$ \\
Item 9 & $0.70^{* *}$ \\
Item10 & $0.71 * *$ \\
Item11 & $0.74 * *$ \\
Item12 & $0.81 * *$
\end{tabular}

Continued

\begin{tabular}{lcc}
\hline \multicolumn{1}{c}{ Processes } & Items & $\begin{array}{c}\text { Correlation } \\
\text { coefficient (r) }\end{array}$ \\
\hline \multirow{2}{*}{ Monitoring } & Item13 & $0.86 * *$ \\
& Item14 & $0.80 * *$ \\
& Item15 & $0.51 * *$ \\
& Item16 & $0.83 * *$ \\
Self-Reflection and & Item17 & $0.83 * *$ \\
Reaction & Item18 & $0.70 * *$ \\
& Item19 & $0.91 * *$ \\
& Item20 & $0.84 * *$ \\
& Item21 & $0.89 * *$
\end{tabular}

** Significant at 0.01 level

The statistical findings in table (12) indicate that there is a significant correlation between the different items and their 
processes at the 0.01 level. Also, it can be noticed that the estimates range between (0.51) and (0.91). This means that there is strong correlation between scores of the different items and the total score of their processes.

b. Using Pearson Correlation, the researcher estimated the correlation coefficient between the score of each process and the total score of the whole questionnaire. The results are shown in table13.

\section{Table2.}

Pearson Coefficients of the Self-Regulation Processes

\begin{tabular}{lc}
\hline \multicolumn{1}{c}{ Processes } & $\begin{array}{c}\text { Correlation } \\
\text { coefficient (r) }\end{array}$ \\
\hline Planning and Activation & $0.98 * *$ \\
Performance & $0.92 * *$ \\
Monitoring & $0.96 * *$ \\
Self-reflection and Reaction & $0.92 * *$ \\
\hline
\end{tabular}

** Significant at 0.01 level

\subsection{Reliability}

To estimate the reliability of the test, the Cronbach's Coefficient Alpha Formula was used. It revealed that the value of Cronbach's Alpha was (0.96). This means that the questionnaire was reliable. Hence, the questionnaire was developed in its final version. Table (3) shows the reliability of the self-regulation questionnaire.

\section{Table3.}

The Reliability of the $S R Q$ 


\begin{tabular}{lcc}
\hline \multicolumn{1}{c}{ Processes } & Items & Cronbach's \\
\hline Planning and Activation & 7 & 0.87 \\
Performance & 5 & 0.81 \\
Monitoring & 5 & 0.83 \\
Self-reflection and Reaction & 4 & 0.85 \\
\hline Self-Regulation Processes scale & 21 & 0.96 \\
\hline
\end{tabular}

\subsection{Analysis}

The questionnaire items were analyzed using the discriminating power for each item in the questionnaire. The researcher used "Mann-Whitney $U$ Test" to compare the means of the two samples that came from the same population and to test whether the two sample means were equal or not. Results are shown in table4. 


\section{الجمعية المصرية للقر اعة والمعرفة عضو الجمعية الدولية للمعرفة}

\section{Table 4.}

The Discrimination of the $S R Q$

\begin{tabular}{|c|c|c|c|c|c|}
\hline \multirow[t]{2}{*}{ Items } & \multicolumn{2}{|c|}{$\begin{array}{c}\text { Low score group } \\
\mathrm{N}=9\end{array}$} & \multicolumn{2}{|c|}{$\begin{array}{c}\text { High score group } \\
\mathrm{N}=9\end{array}$} & \multirow{2}{*}{$\begin{array}{c}\begin{array}{c}\text { Mann- } \\
\text { Whitney } \\
\text { Test }\end{array} \\
\text { Z }\end{array}$} \\
\hline & $\begin{array}{l}\text { Mean } \\
\text { Rank }\end{array}$ & $\begin{array}{c}\text { Sum of } \\
\text { Ranks }\end{array}$ & $\begin{array}{c}\text { Mean } \\
\text { Rank }\end{array}$ & $\begin{array}{c}\text { Sum of } \\
\text { Ranks }\end{array}$ & \\
\hline Item 1 & 13.3 & 119.5 & 5.7 & 51.5 & $3.24 * *$ \\
\hline Item 2 & 13.6 & 122.0 & 5.4 & 49.0 & $3.33 * *$ \\
\hline Item 3 & 13.6 & 122.0 & 5.4 & 49.0 & $3.41 * *$ \\
\hline Item 4 & 13.3 & 120.0 & 5.7 & 51.0 & $3.21 * *$ \\
\hline Item 5 & 13.8 & 124.0 & 5.2 & 47.0 & $3.61 * *$ \\
\hline Item 6 & 13.2 & 119.0 & 5.8 & 52.0 & $3.20 * *$ \\
\hline Item 7 & 13.3 & 120.0 & 5.7 & 51.0 & $3.24 * *$ \\
\hline Item 8 & 12.9 & 116.0 & 6.1 & 55.0 & $2.90 * *$ \\
\hline Item 9 & 14.0 & 126.0 & 5.0 & 45.0 & $3.75^{* *}$ \\
\hline Item 10 & 14.0 & 126.0 & 5.0 & 45.0 & $3.88 * *$ \\
\hline Item 11 & 14.0 & 126.0 & 5.0 & 45.0 & $3.66^{* *}$ \\
\hline Item 12 & 14.0 & 126.0 & 5.0 & 45.0 & $3.85 * *$ \\
\hline Item 13 & 14.0 & 126.0 & 5.0 & 45.0 & $3.89 * *$ \\
\hline Item 14 & 14.0 & 126.0 & 5.0 & 45.0 & $3.75 * *$ \\
\hline Item 15 & 14.0 & 126.0 & 5.0 & 45.0 & $3.93 * *$ \\
\hline Item 16 & 14.0 & 126.0 & 5.0 & 45.0 & $3.83 * *$ \\
\hline Item 17 & 14.0 & 126.0 & 5.0 & 45.0 & $3.85^{* *}$ \\
\hline Item 18 & 14.0 & 126.0 & 5.0 & 45.0 & $3.91 * *$ \\
\hline Item 19 & 14.0 & 126.0 & 5.0 & 45.0 & $3.89 * *$ \\
\hline Item 20 & 14.0 & 126.0 & 5.0 & 45.0 & $3.89 * *$ \\
\hline Item 21 & 14.0 & 126.0 & 5.0 & 45.0 & $3.87 * *$ \\
\hline
\end{tabular}


** Significant at 0.01 level

Table4. shows the results of the "Mann-Whitney Test" which revealed significant differences between the mean ranking scores of students with low and high scores for the items of the self-regulation questionnaire. The " $z$ " values ranged between 2.90 and 3.93. These estimated t-values were statistically significant at the 0.001 level, which means that all the items were considered discriminating items.

\subsection{The Treatment}

The present study was concerned with the use of an online deep learning based-program for developing EFL student teachers' selfregulation processes.

\subsubsection{Aims of the Proposed Program}

a. Helping students recognize the importance of online deep learning in developing self-regulation.

b. Developing self-regulation processes for the EFL $3^{\text {rd }}$ year student teachers at Damietta Faculty of Education using an online deep learning based-program.

\subsubsection{Objectives of the Proposed Program}

The proposed program had certain objectives that would be achieved at the end of the program. These objectives were concerned with developing self-regulation processes. By the end of the proposed program, the student teachers would be able to:

1. Plan and activate their knowledge in a pre-reading phase.

2. Do the task performance effectively in a during-reading phase.

3. Monitor themselves very well in a during-reading phase.

4. Assess their reflection and reaction in a post-reading phase.

\subsubsection{Duration of the Proposed Program's Administration}

The proposed program was administered in the second semester at the academic year 2019-2020. It took place within ten sessions where the student teachers of the experimental group attended the two introductory sessions face to face in the language 
laboratory at Damietta Faculty of Education. Then, they attended the eight sessions online. Each session took about two hours through two periods separately a week; the first period took an hour and a half on Edmodo Site and the second period took a half of an hour by using Zoom Cloud Meetings App. Therefore, the proposed program took about twenty hours in a period of ten weeks. The student teachers of the experimental group received the proposed program for developing their self-regulation processes.

\subsubsection{Description of the Proposed Program}

The proposed program consisted of ten sessions. These sessions aimed at developing the EFL $3^{\text {rd }}$ year student teachers' selfregulation processes. These sessions included eight various passages for developing the EFL $3^{\text {rd }}$ year student teachers' self-regulation processes.

\subsubsection{Content of the Proposed Program}

The content of the proposed program included two introductory sessions and eight various passages. Concerning the passages included in the proposed program, they were selected by the researcher who took into account these criteria: a) they were relevant to the language level of the EFL $3^{\text {rd }}$ year student teachers; b) they were relevant to the students' background knowledge and culture; and c) they were selected to motivate the students and their interests. Table5. shows the content that was included in the proposed program.

\section{Table16.}

Content of the Proposed Program 
الجمعية المصرية للقر اعة والمعرفة عضو الجمعية الدولية للمعرفة ILA

Sessions of the

\section{Title of Session}

Proposed Program

Session One An Introductory Session on Critical

Reading Skills and Self-Regulation

Session Two

An Introductory Session on Deep

Learning and Online Learning

Session Three

Money Can't Buy Love

Session Four

Session Five

Session Six

Session Seven

Public Trust in the News

Why Birds Fly in a V Formation

Saving Our Cities and Ourselves

from the Automobile

Session Eight

Session Nine

Democracy

Why You Shouldn't Trust Internet

Comments

Session Ten

The Possibility of Locating Intelligent

Life on Other Planets

Source: Original

\subsubsection{Steps Followed in Designing the Proposed Program \\ Sessions}

In designing the ten sessions of the proposed program, the researcher followed these steps:

$a$. Two orientation sessions: At the beginning of the experiment, two introductory sessions were conducted by using data show in the language laboratory at Damietta Faculty of Education and took about two hours each. The researcher used power point slides to present, a deep learning approach, its model and its strategies, and online learning and its approaches. In addition to that, she taught them how to use Edmodo Site and to join Zoom Cloud Meetings app. 
b. The researcher used an online deep learning based program that depends four strategies (Jagsaw Strategy, AICDR Strategy, Graphic Organizer Strategy, and Talk Show Strategy) as shown in figure2. for developing the EFL $3^{\text {rd }}$ year student teachers' selfregulation processes.

c. The researcher implemented eight various passages in the sessions of the proposed program.

d. Each session of the program was divided into three stages; prereading stage, during-reading stage and post-reading stage. In a pre-reading stage, learners were divided into six main groups. Each main group had five learners. They set goals, planned and activated their knowledge, and estimated how much each task would be.

In a during-reading stage, the teacher divided the passage into five parts and asked the members of each original jigsaw group to study the assigned parts independently by asking themselves meaningful questions that were inspired by curiosity about new experiences, gathering information about them, searching online resources, and creating new knowledge and making a report about the findings of their investigation. After that, the teacher asked them to move to the expert groups to discuss the parts in detail by sharing their new ideas with others and asking them about their own experiences, take the time to look back at the questions, and make new decisions. Next, the teacher asked learners to return to their original jigsaw groups to take turns teaching about their portion of the passage. Each original Jigsaw group was asked to do a graphic organizer of the passage as a whole and upload it on the Edmodo website.

In a post-reading stage, learners are asked to meet together in the online talk show episode. One learner would be the host. Two or three learners would be the guests. Then, the rest of the learners would be the audiences. This episode discussed the same subject that learners had learned from the session with a different point of view. Therefore, they could deepen their understanding and asked 
further questions. They could relate what they had learned to their own experiences and created new knowledge. At last, learners self-assessed their task performance by themselves, judged what they had done to the pre-set goals, chose the best ways to use in next tasks, and learned from their mistakes.

d. The researcher developed EFL $3^{\text {rd }}$ year student teachers' selfregulation processes in each session.

e. The researcher implemented several assignments and quizzes designed by the researcher in the ten sessions of the proposed program.

g. The researcher discussed the answer of the questions with the students to give them more opportunities for promoting selfregulation.

\subsubsection{Electronic Aids and Equipment}

The researcher used some electronic aids and equipment such as: computers and a data show projector (introductory sessions), Edmodo Website, pictures, Pdf Document, Word Document, Google Search Site, Google Translate Site, Zoom Cloud Meetings App. 
ILA الجمعية المصرية للقر اعة و المعرفة عضو الجمعية الدولية للمعرفة

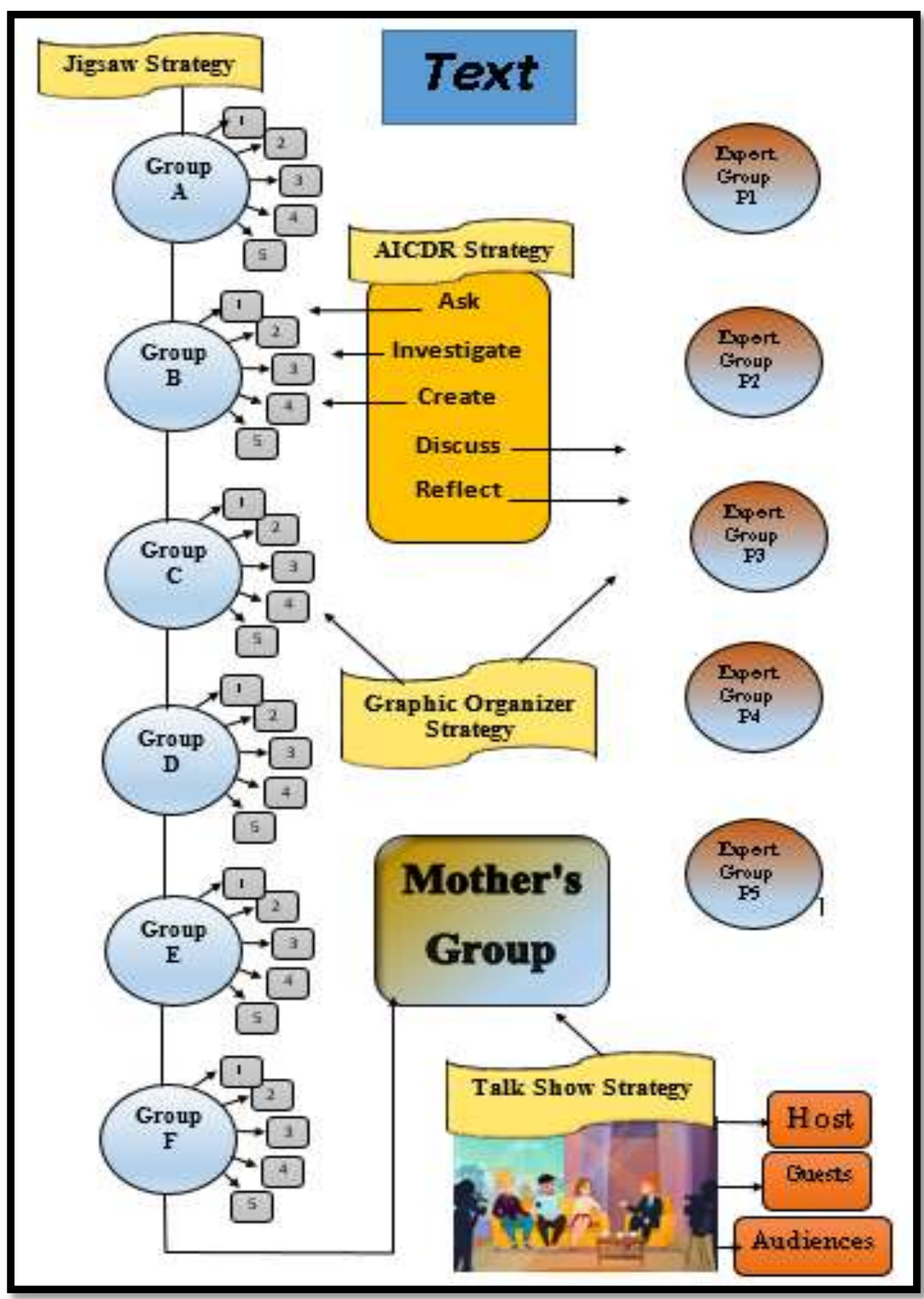

- M - 
Figure 1. Online Deep Learning Strategies

Source: Original

\section{Results and Discussion}

\section{- Analyzing the Results for Testing the First Hypothesis}

The first hypothesis stated that: "There is a statistically significant difference, at the significance level of $p \leq 0.05$, in the selfregulation post-questionnaire, between the mean score of the experimental group and those of the control group in favor of the experimental group".

The t-test of independent samples was used to test the first hypothesis which addresses the differences between the mean score of the experimental group and those of the control group in the postmeasurement of the self-regulation questionnaire. Table (6) shows the differences:

\section{Table6.}

Comparing the Performance of the Two Groups on the PostMeasurement of the SRQ.

\begin{tabular}{|c|c|c|c|c|c|}
\hline \multirow{2}{*}{ Processes } & \multirow{2}{*}{ Study groups } & \multirow{2}{*}{ Mean } & \multirow{2}{*}{ SD } & \multicolumn{2}{|c|}{ t-test } \\
\hline & & & & $\mathbf{t}$ & DF \\
\hline \multirow{2}{*}{$\begin{array}{l}\text { Planning and } \\
\text { Activation }\end{array}$} & Experimental group & 29.63 & 1.81 & \multirow{2}{*}{$22.16^{* *}$} & \multirow{2}{*}{58} \\
\hline & Control group & 17.27 & 2.46 & & \\
\hline \multirow{2}{*}{ Performance } & Experimental group & 20.13 & 1.63 & \multirow{2}{*}{$14.72 * *$} & \multirow{2}{*}{58} \\
\hline & Control group & 12.00 & 2.55 & & \\
\hline \multirow{2}{*}{ Monitoring } & Experimental group & 20.57 & 1.68 & \multirow{2}{*}{$16.30 * *$} & \multirow{2}{*}{58} \\
\hline & Control group & 12.03 & 2.33 & & \\
\hline Self-reflection & Experimental group & 16.77 & 1.48 & $18.11 * *$ & 58 \\
\hline
\end{tabular}




\begin{tabular}{llcccc} 
and Reaction & Control group & 9.27 & 1.72 & & \\
\hline Self-Regulation & Experimental group & 87.10 & 3.90 & \multirow{2}{*}{$27.84^{* * *}$} & \multirow{2}{*}{58} \\
Questionnaire & Control group & 50.57 & 6.04 & & \\
\hline
\end{tabular}

** Significant at 0.01 level

Results in Table (6) reveal that the mean score of the experimental group was (87.10) which was noticeably high and statistically significant compared to that of the control group $(\mathrm{m}=50.57)$ and $\mathrm{t}$-value was (27.84). In addition, the experimental group outperformed than the control group in all such processes of the SRQ. 


\section{- Analyzing the Results for Testing the second Hypothesis}

The fourth hypothesis stated that: "There is a statistically significant difference, at the 0.05 level between the self-regulation performance of the experimental group on the pre-and postadministration of the self-regulation questionnaire in favor of the post-administration".

To verify the fourth hypothesis, the t- test of paired samples was used for comparing the difference between the mean score of the experimental group on the pre-and post-administration of the SRQ. For more details, Table21 shows the comparison of the performance of the experimental group in the pre- and post- measurements.

\section{Table7.}

Comparing the Performance of the Experimental Group on the Preand Post-Measurement of the SRQ

\begin{tabular}{llcccc}
\hline \multirow{2}{*}{ Processes } & Measurement & \multirow{2}{*}{ Mean } & \multirow{2}{*}{ SD } & \multicolumn{2}{c}{ t-test } \\
\cline { 5 - 6 } Planning and & Pre-measurement & 17.30 & 2.31 & \multirow{2}{*}{ t $2.98^{* *}$} & 29 \\
Activation & Post-measurement & 29.63 & 1.81 & & \\
\multirow{2}{*}{ Performance } & Pre-measurement & 12.10 & 2.54 & $19.68^{* *}$ & 29 \\
& Post-measurement & 20.13 & 1.63 & & \\
\multirow{2}{*}{ Monitoring } & Pre-measurement & 12.47 & 2.61 & $16.01^{* *}$ & 29 \\
Self-Reflection and & Post-measurement & 20.57 & 1.68 & & \\
Reaction & Pre-measurement & 9.13 & 1.76 & $18.96^{* *}$ & 29 \\
\hline Self-Regulation & Pre-measurement & 51.00 & 6.14 & \multirow{2}{*}{$34.87^{* *}$} & 29 \\
Questionnaire & Post-measurement & 87.10 & 3.90 & & \\
\hline
\end{tabular}

** Significant at 0.01 level 
A closer look at table (7) shows that the estimated t-value was significant at the $\mathrm{p} \leq 0.001$ level, in all individual SRQ processes on the pre-and post-administration of the SRQ in favor of the postmeasurement.

The results of the first and second hypotheses indicated that the experimental group students outperformed their counterparts in the control group on the post (SRQ). These results could be ascribed to the implementation of the (ODLBP). It provided the students the opportunity to plan and activate their knowledge, perform the tasks successfully, monitor their behaviors in terms of their goals, manage their time, and self-reflect on their actions. It also stimulated students' intrinsic motivation towards learning. Different activities were presented through the stages of reading process such as "Monitoring Chart" in assignment 5, and "Reflection Log" in quiz 5.

This indicates that the proposed program was effective in developing the self-regulation processes among the students of the experimental group.

The results of the study were consistent with different studies adopting online deep learning to enhance self-regulation processes such as Magno (2009), Trigwell, Ellis and Han (2012), Ekici, Coskun and Yurdugul (2014), and Kollerup (2015), Barak, Farraj and Dori (2016), Naseri and Motallebzadeh (2016), and Barboza, Torres, Nunez and Martinez (2017).

\section{Conclusions}

1. The present study provided evidence to the impact of using (ODLBP) in developing EFL students' self-regulation. 


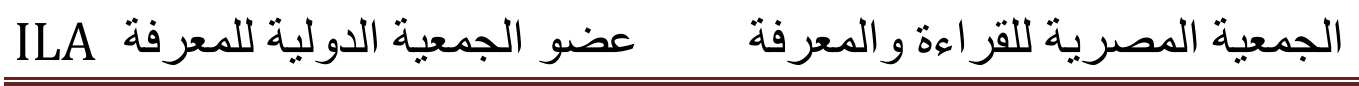

2. Online deep learning is effective in improving EFL students' selfregulation.

3. Online training programs are effective in improving EFL students' self-regulation.

4. Online training programs are effective environments for regulating students' strategic behavior to be autonomous language learners.

5. Online deep learning is more effective in developing students' meta-cognitive and analytic skills, and stimulating their enthusiasm and motivation.

6. Online deep learning is more effective in developing students' independent and systematic thinking and logical reasoning skills.

7. Online deep learning is more effective in helping the learners build a sense of leadership, ownership, and responsibility towards their learning.

8. The ODLBP presented a unique opportunity to combine four effective instructional techniques (Jigsaw, AICDR, Graphic organizer, and Talk Show) together using some modern technologies such as Edmodo platform and Zoom Cloud Meetings App.

9. The ODLBP made the students be self-regulators who had selfgenerated thoughts, feelings and actions, self-judgment, selfobservation, and self-reaction.

\section{References}

Allen, P. (2011). Understanding the relationship between students' reading achievement and teachers' self-regulation patterns in grades K-3. Published doctoral dissertation, Southern Mississippi University, Hattiesburg, Mississippi.

Barak, M. Farraj, R. \& Dori, Y. (2016). On-campus or online: examining self-regulation and cognitive transfer skills in 
different learning settings. International Journal of Educational Technology in Higher Education, 13 (35), 119.

Barboza, E. Torres, J. Nunez, J. \& Martinez, T. (2017). Actions and achievements of self-regulated learning in personal environments. Research on students participating in the Graduate Program in Preschool Education at the University of Granada. Journal of New Approaches in Educational Research, 6 (2), 13-143.

Bartolome, A. \& Steffens, K. (2011). Technologies for self-regulated learning. In R. Carneiro, P. Lefrere, K. Steffens \& J. Underwood (Eds), self-regulated learning in technology enhanced learning environments (pp.21-31). Rotterdan: Sense Publishers.

Biggs, J. (1987). Student approaches to learning and studying. Hawthorn, Victoria: Australian Council for Educational Research.

Biggs, J., Kember, D., \& Leung, D. (2001). The revised two-factor study process questionnaire: R-SPQ-2F. British Journal of Educational Psychology, 71, 133-149.

Baki, M. Shear, L. Toyama, Y. \& Lasseter, A. (2012). Understanding the implications of online learning for educational productivity. Retrieved November $18^{\text {th }}, 2017$ from https://tech.ed.gov/files/2013/10/implications-onlinelearning.pdf

Bruce, B. \& Bishop, A. (2003). Using the web to support inquirybased literacy development. Journal of Adolescent \& Adult Literacy, 45(8), 208-221.

Casey, L. \& Bruce, B. (2011). The practice profile of inquiry: connecting digital literacy and pedagogy. E-Learning and Digital Media, 8(1), 76-85. 
Chang, E. (2002). The efficacy of asynchronous online learning in the promotion of critical thinking in graduate education, Published doctoral dissertation, Teachers College, Columbia University, New York City, New York.

Edutech Wiki (2019). Inquiry based learning. Retrieved January $15^{\text {th }}$ 2020 from http://edutechwiki.unige.ch/en/Inquirybased_learning

Ekici, M., Coskun, H., \& Yurdugul, H. (2014). Investigation of the relationship between learning approaches and online selfregulation behaviour. Procedia - Social and Behavioral Sciences, 141, 285-289.

Ellis, E. (1999). Using graphic organizers to make sense of the curriculum. Tuscaloosa, AL: Masterminds, LLC.

Friedman, D. Crews, T. Caicedo, J. Besley,J. Weinberg, J. \& Freeman, M. (2019). An exploration into inquiry-based learning by a multidisciplinary group of higher education faculty, Higher Eduction, 59, 765-783.

Hedeen, T. (2003). The reverse jigsaw: a process of cooperative learning and discussion, Teaching Sociology, 31(3), 325332.

Hanover Research Council. (2009). Best practices in online teaching strategies. Retrieved November 19th, 2017 from www.uwec.edu/.../Best-Practices-in-Online-TeachingStrategies-Mem...

Hermida, J. (2016). Strategies to promote a deep approach to reading. Retrieved December $23^{\text {rd }}, 2016$ from commons.trincoll.edu/.../WEEK-2-Strategies-to-Promotea-Deep-Approach-to-Readin...

Horner, S., \& Shwery, C. (2002). Becoming an Engaged, SelfRegulated Reader. Theory In to Practice, 41(2), 102-109. Retrieved July 30, 2020, from www.jstor.org/stable/1477461 
Ilie, C. (2006), Talk Shows. In: Keith Brown, (Editor-in-Chief) Encyclopedia of Language \& Linguistics, Second Edition, 12, pp. 489-494. Oxford: Elsevier.

Kaufman, R. \& Wandberg, R. (2010). Graphic organizers.

In Powerful practices for high-performing special educators (pp. 99-116). Thousand Oaks, CA: Corwin Press doi: $10.4135 / 9781483350455 . n 7$

Keshta, A. (2016). The impact of using jigsaw strategy on improving reading comprehension and communication skills among eleventh graders in Rafah, Published master's thesis, The Islamic University, Gaza, Palestine.

Kitsantas, A. (2013). Fostering college students' self-regulated learning with learning technologies. Hellenic Journal of Psychology, 10, 235-252.

Kollerup, J. (2015). Problem-based learning and deep learning approach in relation to self-directed learning. Published master's thesis, Aalborg University, Aalborg, Denmark.

Leamnson, R. (2004). Learning (Your first job). Retrieved November $\quad 17^{\text {th }}, \quad 2016, \quad$ from http://ctl.uga.edu/pages/learning-your-first-job

Ley, K., \& Young, D. (2001). Instructional Principles for SelfRegulation. Educational Technology Research and Development, 49 (2), 93-103. Retrieved July 30, 2020, from www.jstor.org/stable/30220313

Li, Q. Moorman, L. \& Dyjur, P. (2010). Inquiry based learning and e-mentoring via video conference: a study of mathematics and science learning of Canadian rural students. Education Tech Research Dev, 58, 729-753.

Liao, J. (2011). Phase state of TV talk show in the oral communication training in the diversion. Published doctoral dissertation, Hunan Normal University, Changsha, Hunan, China. 
Lindblom-Yanne, S., \& Pihlajamaki, H. (2003). Can a collaborative network environment enhance essay-writing processes? British Journal of Educational Technology, 34(1), 17-30.

Magno, C. (2009). Self-regulation and approaches to learning in English composition writing. TESOL Journal, 1, 1-16.

Means, B. Toyama, Y. Murphy, R. and Baki, M. (2013). The effectiveness of online and blended learning: a metaanalysis of the empirical literature.Teachers College Record, 115(030303), 1-47.

Naseri, S., \& Motallebzadeh, K. (2016). Podcasts: a factor to improve Iranian EFL learner' self-regulation ability and use of technology. Educational Technology \& Society, 19 (2), 328-339.

Nimehchisalem, V. (2013). The talk show method in the ESL classroom. Voices in Asia Journal, 1(1), pp.57-71.

Ozhiganova, G. (2018). Self-regulation and self-regulatory capacities: components, levels, models. RUDN Journal of Psychology and Pedagogics, 15 (3), pp. 255-270.

Paris, S. and Paris, A. (2001). Classroom applications of research on self-regulated learning. Educational Psychologist, 36 (2), 89-101.

Perkins. D. \& Saris, R. (2001). A “jigsaw classroom” technique for undergraduate statistics courses, Teaching of Psychology, 28(2), 111-113.

Rossen, E. \& Hartley, D. (2001). Basics of e-learning. United States of America, U.S.: the American Society for Training \& Development Press.

Sahabudin, N. \& Ali, M. (2012). Combination of two learning approaches which are self-regulated learning and personalized learning (SRPL). Paper presented at international conference on management and education 
innovation (ICME), May, 5-6, IPEDR, 37, IACSIT Press, 1-5, Singapore.

Syahadati, E. (2015). The use of talk show video as a reflective practice to improve students' vocabulary in English speaking skill. Published thesis's master, English Education Department, Graduate School, Sebelas Maret University, Surakarta, Central Java, Indonesia.

Tobar, M. \& Moya, N. (2017). Graphic organizers as a reading strategy: Research findings and issues. Revista Publicando, 4 (12), pp.247-258.

Torres, D. (2015). Effectiveness of the use of graphic organizers and summaries: a case study of adult EFL students in a reading comprehension course. Revista de Lenguas Modernas (22), 267-295.

University of Massachusetts. (2002). Teaching and learning online communication, community, and assessment: a handbook for UMass Faculty. Massachusetts, MA: Amherst Mass.

Xiaoming, D. \& Zhuo, C. (2017). Teaching virtual experiments: from course design to learning assessment, iJOE, 13(8), 31-44.

Zimmerman, B. J. (2000). Attaining self-regulation: A social cognitive perspective. In M. Boekaerts, P. R. Pintrich, \& M. Zeidner (Eds.), Handbook of self-regulation (pp. 1339). San Diego, CA: Academic Press. 